EGU2020-13887

https://doi.org/10.5194/egusphere-egu2020-13887

EGU General Assembly 2020

(c) Author(s) 2021. This work is distributed under

the Creative Commons Attribution 4.0 License.

\title{
Degradation of concrete with glass enriched recycled aggregate used to flooring an industrial warehouse in Italy
}

Elena Marrocchino, Negar Eftekhari, and Carmela Vaccaro

University of Ferrara, Department of Physics and Earth Science, Italy (mrrlne@unife.it)

This research investigates as chemical and mineralogical properties can affect degradation of concrete, made using secondary aggregates derived from recycled, in the enforcement of Waste Framework Directive (WFD) 2008/98/EC. High volumes of C\&D require the use of waste in various productive contexts. The utilisation of secondary materials derived from CDW recycling in flooring of industrial warehouse can reduce the environmental impacts of quarrying extractions. In recent years, the use of waste in the packaging of mortars and conglomerates has been increased and many companies offer the incorporation of waste glass as aggregate for concrete and mortars. There is still scientific debates on the opportunity to use glass related to the influence on workability and there are some concerns on the durability and resistance to degradation of products made with non-natural aggregates in conditions of interaction with alkali-rich waters.

In this work mineralogical-petrographical analyses have been carried out on sample and have shown that:

- use of glass influences compaction factors, therefore there is an increase in the air content also due to the involvement of numerous small particles. This produces high macroscopic and nanometric porosity, observed both on thin sections microscope observations and on SEMEDSanalyses, which affects compressive, tensile and flexural strength of mortars and concrete in proportion to the content of waste glass used.

- microcracks in glass aggregates, produced by crushing, increase aggregate water interaction surface, so it tends to degrade more easily by hydrolysis, moreover the greater permeability to air and water accelerates carbonation processes.

- smooth surface of the waste glass decreases the adhesion force between glass surface cement.

- addition of waste glass to natural aggregates produces an improvement in workability due to the non-absorbent nature of the glass.

- In the short time inclusion of glass aggregates effectively improves the surface resistivity and the attack on sulphate but in the long time a secondary porosity for hydrolysis intervenes and the resistance decreased, and the carbonation rate increases.

- contraction from drying of the concrete decreases with the content of glass aggregates 
increasing, but subsequently the swellings by hydrolysis can produce a secondary porosity giving an intimate and widespread fracturing of the matrix

Petrographical both on thin sections and on crushed samples observation and SEM-EDS microanalysis have shown that degradation is due to the use of crushed natural aggregate mixed with recycling aggregate rich in common glass. This degradation has provided that alkaline elements interact with cement and with siliceous aggregates of the screed. It has been also noted that degradation is accelerated by the widespread presence of sulphur, sometimes in high concentrations and due to the use of recycled material, and the presence of iron. Degradation differences depend on a heterogeneous distribution of the C\&D waste aggregate, so in the areas where it is less abundant, the phenomenon is less striking. 